\title{
0 riso e a ironia no relato de Marcos 5.1-20
}

\section{Laughter and irony in the account of Mark 5: 1-20}

Risas e ironía en el relato de Marcos 5.1-20

\author{
Paulo Sérgio Macedo dos Santos*
}

Foi dito que refletir sobre o riso faz ficar melancólico.

Joachin Ritter, 1940

\begin{abstract}
RESUMO
Os estudos bíblicos avançaram muito sobre a seara da crítica literária nos últimos tempos. As funções narrativas do texto, bem como a diversidade de gêneros literários que os compõe, foram analisadas sob diversos prismas. A utilização de ferramentas da crítica literária moderna colabora para a imersão em níveis mais profundos daquilo que pode ser motivador na feitura do texto, que vão desde a construção mítica do arquétipo do herói, passando pela influência de outras culturas, até a presença da cultura popular. Poucas são as pesquisas que se debruçaram sobre as características do risível presente nessas construções narrativas. $O$ presente estudo não tem a pretensão de exaurir todas as questões sobre o tema do riso em textos sagrados. Antes, procura relacionar a presença clara de aspectos do riso e do risível, da ironia e do sarcasmo como constantes no Evangelho de Marcos 5.1-20, evidenciando aquilo que, para alguns críticos do riso (Henri Bergson, Georges Minois, Quintiliano, entre outros), denota a presença da ironia, do chiste e do risível como elementos narrativos. A dicotomia imposta pelos estudos clássicos dificulta a interconexão de estilos como sério e risonho, e pode ser justificada por outra dicotomia que divide o mundo entre sagrado e profano. Neste artigo, busca-se refletir que nos ambientes criativos essas divisões são artificiais e esvaziadas de sentido.
\end{abstract}

Palavras-chave: Riso; comicidade; textos sagrados; Evangelho de Marcos.

\begin{abstract}
Biblical studies have come a long way in the field of literary criticism in recent times. The narrative functions of the text, as well as the diversity of literary genres that compose them, were analyzed from different perspectives. The use of modern literary criticism tools has contributed to the immersion in deeper levels of what can be motivators in the making of the text, from the mythical construction of the hero archetype, through the influence of other cultures and to the presence of popular culture. Few researches have investigated the characteristics of the laughable present in these texts. This study does not claim to exhaust all possibilities about laughter in sacred texts. It seeks to relate the clear presence of aspects of laughter and laughability, irony and sarcasm as they appear in the Gospel of Mark 5.1-20, showing what, for some critics of laughter (Henri Bergson, Georges Minois, Quintiliano, among others), denotes the presence of irony, joke and laughter as narrative elements. The dichotomy imposed by classical studies that hinder the interconnection of styles like serious and smiley can be justified by the same dichotomy that divides the world between sacred and
\end{abstract}

* Teólogo, mestre e doutorando em Ciências da Religião pela Universidade Metodista de São Paulo (Umesp). Bolsista Capes. E-mail: pasesan@gmail.com 
profane. In this paper we have tried to reflect that in creative environments these divisions are artificial and emptied of meaning.

Keywords: Laughter; comic; Sacred Texts; Gospel of Mark.

\begin{abstract}
RESUMEN
Los estudios bíblicos han recorrido un largo camino en el campo de la crítica literaria en los últimos tiempos. Las funciones narrativas del texto, así como la diversidad de géneros literarios que lo componen, se analizaron desde diferentes perspectivas. El uso de herramientas de crítica literaria moderna contribuye a la inmersión en niveles más profundos de lo que puede ser motivador en la elaboración del texto, desde la construcción mítica del arquetipo del héroe, pasando por la influencia de otras culturas hasta la presencia de la cultura popular. Pocas investigaciones han analizado las características del risible presente en estas construcciones narrativas. El presente estudio no pretende agotar todas las preguntas sobre el tema de la risa en los textos sagrados. Antes, busca relatar la presencia clara de aspectos de la risa y del risible, la ironía y el sarcasmo como constantes en el Evangelio de Marcos 5.1-20, mostrando lo que para algunos críticos de la risa (Henri Bergson, Georges Minois, Quintiliano, entre otros) denota la presencia de ironía, broma y risa como elementos narrativos. La dicotomía impuesta por los estudios clásicos dificulta la interconexión de estilos como serio y risueño, y puede justificarse por otra dicotomía que divide el mundo entre lo sagrado y lo profano. Este artículo busca reflejar que en ambientes creativos estas divisiones son artificiales y están desprovistas de significado.
\end{abstract}

Palabras clave: Risa; comicalidad; textos sagrados; Evangelio de Marcos

\title{
Introdução
}

O riso, nos últimos tempos, vem ocupando um espaço maior nas pesquisas acadêmicas, tanto pelas motivações que o produzem, como pelos efeitos produzidos. Historiadores, antropólogos e cientistas sociais passaram a se debruçar sobre os aspectos do riso e do risível na construção do ser e da sociedade. A análise do riso e do risível rompe com preconceitos anteriores e começa a ser objeto de pesquisa nas histórias dos palácios, nos personagens históricos e nas entranhas das relações sociais e de poder. Ultimamente e de maneira tímida, essa perspectiva começa a ser vista nos estudos da religião.

Durante muito tempo os estudos da religião se predispuseram a aceitar a dicotomia do sagrado/profano. Também nos estudos sobre o riso, partiu-se do axioma bipartido do sério/risonho. A cultura ocidental, herdeira do helenismo aristotélico que coloca o cômico como um caractere inferior, com menor valor que o trágico, influencia sobremaneira o conceito dualista sério/risonho. Existindo essa divisão, faz-se mister compreender a religião como sendo coisa séria/sagrada, dando ao cômico a desimpôrtancia do risonho/profano.

Essas perspectivas são dependentes. Os estudos do riso sempre ocuparam um local periférico nas pesquisas. A frase recorrente aos estudos da religião: "religião é coisa séria" encontra equivalência com "política é coisa séria"; "trabalho é coisa séria"; "pesquisa é coisa séria”; por fim, a mais genérica de todas: "agora é sério". O riso, assim, torna-se, apesar de estar presente em todas as esferas sociais e culturais, objeto de intervalo, de en- 
tretenimento, de descanso, de prazer efêmero que não pode e nem deve ser estudado. Apesar de onipresente, não passa de um marginal.

\section{Por que rimos e do que rimos}

Charles Darwin, em sua obra Expression of the emotions in man and animals, buscou, por meio de experimentos, mostrar que o riso pode ser uma resposta fisiológica a um estímulo externo. Isso é percebido, segundo ele, em qualquer animal. Ao observar macacos estimulados por cócegas, Darwin notou que estes produziam na face as mesmas reações fisiológicas do riso em humanos: cantos da boca elevados, dentes exibidos sem ataque prenunciado, emissão de sons guturais. Para o naturalista britânico, o fato de os símios serem capazes de rir corroborava a teoria de evolução por ele proposta. Para Darwin, o riso é uma resposta fisiológica a estímulos físicos, podendo ser observado em uma diversidade de espécies, e uma resposta igualmente fisiológica para estímulos intelectuais no caso dos humanos.

O pensamento comum de certas expressões em espécies distintas, embora aliadas, como nos movimentos dos mesmos músculos faciais durante o riso pelo homem e por vários macacos, torna-se um pouco mais inteligível se aceitarmos em sua descendência um progenitor comum (DARWIN,1872, p. 12).

O riso, na análise fisiológica e em concordância com a teoria de Darwin, é uma resposta corporal não-racional. Para muitos de seus detratores, uma "emoção" a ser combatida, um ato absolutamente irracional.

Henri Bergson, na obra $O$ riso, tem contribuição fundamental acerca do que nos faz rir. Ele afirma que o ser humano é o único animal capaz de rir e de fazer rir. Como se nota, a hipótese de Bergson se torna irreconciliável com a de Darwin: o riso é uma capacidade intelectual, portanto, o ser humano o faz de maneira consciente.

Em sua crítica, Bergson prioriza o estudo do riso pelo cômico, por aquilo que é capaz de produzir o riso pela atividade intelectual, seja na construção de uma narrativa, seja na observação de um fato. Discorda de Darwin quando este considera a possibilidade de os macacos rirem. Para Bergson, o riso produzido pelos símios nada mais é do que um espasmo, que pode ser observado em uma criança que ainda não desenvolveu a capacidade de cognição.

(...) não há comicidade fora do que é propriamente humano. Uma paisagem poderá ser bela, graciosa, sublime, insignificante ou feia, porém jamais risível. Riremos de um animal, mas porque teremos surpreendido nele uma atitude de homem ou certa expressão humana (BERGSON, 1980, p. 7). 
O riso, sendo uma resposta à atividade racional provocada pelo cômico, conforme Bergson defende, pode ser visto como um elemento da cultura: envolto nos seus limites, muitas vezes brincando perigosamente nas margens, provocando inquietações e questionamentos em aspectos do risível como, por exemplo, na ironia e no sarcasmo.

Em O riso, Bergson busca apreender os processos envolvidos na produção do "cômico", sugerindo que, fundamentalmente, a mecanicidade e a rigidez em contraposição à maleabilidade do vivo, o automatismo contrastado com a atividade viva, são os elementos ressaltados pelo riso. O humano que se comporta como uma máquina ou um animal que se comporta como humano são capazes de produzir o riso. Em Bergson, ao se colocar os limites da cultura de maneira tão clara, o riso passa a ser uma forma de vingança sobre esses limites estruturais. "A sociedade vinga-se, por meio do riso, das liberdades que se tomaram com elas. Ela não atingiria seu objetivo se carregasse a marca da solidariedade e da bondade" (BERGSON, 2001, p. 100).

O riso possui também o poder de delimitar espaços, desde que seja possível se educar para ele. Ensinando-se os limites que os padrões culturais e éticos impõem, termina-se por ensinar o quanto se pode jogar nessa fronteira. O riso acaba por ser ensinado. Todo objeto da cultura, conforme Aristóteles afirma, é transmitido através da imitação (mimeses) (ARISTÓTELES, 1999). O riso permite, dessa maneira, abrir pequenas brechas no limite da cultura. Esse limite tênue é capaz, via de regra, por questões éticas e morais, de determinar a diferenciação entre o riso e o escândalo, entre a piada de mau gosto e a barbárie. São esses limites que impõem um mínimo de controle.

(...) a sociedade se sente obrigada a manifestar-se. Impõe-se, pois, que haja na causa da comicidade algo de ligeiramente atentatório (e de especificamente atentatório) à vida social, dado que a sociedade reage a isso por um gesto que tem todo o aspecto de uma reação defensiva, por um gesto que causa leve medo (BERGSON, 2001, p. 105).

\section{O riso como fronteira do sagrado e do profano}

Aristóteles na sua Poética e Platão na República partilham da mesma noção de que o riso pressupõe um sentimento de superioridade em relação ao seu objeto. Partindo dessa perspectiva, o riso pode ser visto como um amalgamador de distinções socioculturais e delimitador de fronteiras, onde é capaz de atuar. A análise de Bergson faz coro com essa concepção: sendo o riso uma atividade racional, ele pode, de maneira mais rápida, levar a questionamentos do tipo: "Estou rindo disso?", e, assim, jogando no limite da cultura, gerar consciência e, de certa maneira, vingar-se dessas demarcações. 
No campo das ciências sociais, somente nos últimos tempos o riso passou a ser utilizado como fonte primaria de estudos sobre a movimentação social e a construção da sociedade. Para Elias Tomé Saliba, a historiografia contribui de maneira decisiva para que os estudos acerca do riso lancem luz, por meio de uma diversidade de registros, sobre o valor inestimável que ele possui. Segundo Saliba,

(...) é todo um variado espectro de fontes para mostrar o quanto o humor incentivou laços da sociedade, sublimou agressões ou ressentimentos, administrou o cinismo ou estilizou a violência. Mas também foi arma social e política dos impotentes, contribuindo para criar uma cultura da divergência ativa e oculta (SALIBA, 2017, p. 20).

Os limites impostos pelas narrativas escritas, segundo Saliba, dificultam esse trabalho. O cômico no texto acaba por suplantar o cômico da vida. Os textos que chegam até nós não permitem o envolvimento na atmosfera do riso em que foram produzidos. Qualquer piada escrita é infinitamente mais sem graça que uma piada contada "ao vivo". A pantomima, a mímica e a imitação jocosa do contador têm que ser levadas em conta. Esses recursos estão impregnados de aspectos risíveis e, em certos casos, envoltos na atmosfera crítica que flerta com os limites da cultura. O riso torna-se linguagem poderosa ao mostrar claramente os limites impostos pela sociedade. Quentin Skinner afirma que:

O riso começou a ser visto como um tipo de grosseria nos dois sentidos do termo: tanto como um exemplo de incivilidade e indelicadeza quanto como uma reação descontrolada e, portanto, bárbara que precisava, numa sociedade educada, ser dominada e, de preferência, eliminada (SKINER, 2002, p. 72).

Existe um limite em que o riso pode agir. A partir do momento em que ele possa provocar questionamento, ou até desestruturar a "ordem", é necessário pará-lo, combatendo-o. Transformar o cotidiano, as relações sociais e os limites impostos como elementos risíveis denota a capacidade questionadora do riso, e a religião não se isenta desses princípios.

Tanto Georges Minois, em sua obra História do riso e do escárnio, como José Rivair Macedo, em seu artigo "Riso ritual, cultos pagãos e moral cristã na Idade Média”, utilizaram o Papiro Mágico XXII para ilustrar a presença do riso no sagrado. Nesse papiro, o mundo é criado por um demiurgo que, a cada riso, cria um deus e um elemento da natureza. Quanto mais ri, mais cria. No sétimo riso, ri tanto que chora. De uma lágrima surge Psique, a alma humana, e a serpente que tudo sabia. O deus que ri de seu próprio absurdo, ri do absurdo de sua criação (MINOIS, 2013) 
A análise feita por Minois e Macedo mostra que, no ambiente multicultural da criação desses textos, os limites impostos posteriormente não podem servir de embasamento para a sua compreensão única. A criação pertence a um lugar de interpenetração cultural, espaço de criação e vivência das mais diversas expressões humanas, o que corrobora as teorias de borda de semiosfera, de Yuri Lotmann (1986), e de entre lugar, de Homi Bhabha (1998). Nesse ponto de encontro de culturas distintas, de maleabilidades fronteiriças, expandem-se os limites do risível.

Os recentes estudos sobre a literatura bíblica, principalmente os que se debruçam sobre a sua recepção, vêm relacionando esses textos com o entorno cultural do cristianismo primitivo, levando em conta a "atmosfera" de produção desses textos, seus referenciais literários, míticos e culturais, não considerando que eles sejam produtos cristalizados. Essa análise amplia os conceitos no tocante à produção cultural do período de elaboração/registro.

Para Paulo Nogueira, a literatura religiosa deve ser vista como um produto da cultura. A religião passa a ser um texto e sua compreensão deve expandir os limites impostos pela interpretação clássica, que ocorre a partir da canonização deles. A sacralização/canonização desses textos é absolutamente artificial, visto que, na sua produção, os elementos que colaboraram na composição do imaginário religioso eram anárquicos para os padrões vigentes, representavam uma ruptura com a hierarquia, sem acatar, de antemão, as barreiras impostas de sagrado/profano, sério/risonho. No âmbito da cultura popular onde esses textos foram gerados, essas barreiras inexistem. $\mathrm{Na}$ cultura popular, mesmo na criação de narrativas sagradas, não se omite o riso. A conceituação de "sagrado" e "sério" se configura mais na recepção do que na criação do texto, ou seja, os padrões culturais nos quais estamos inseridos configuram a forma que interpretamos esses textos.

O conceito de sagrado da modernidade é, para Mikhail Bakhtin (1987), moldado na Idade Média, que também configurou a forma como o riso é visto no Ocidente. A diabolização do riso ocorre como forma de controlá-lo, de impedir que as delimitações fronteiriças sejam ameaçadas. A carnavalização a que Bakhtin se refere, a suspensão de tempo, inversão e convivência de papeis sociais, deve ser vista como um dos elementos importantes na construção da narrativa. O risível faz parte do ambiente de criação dos textos sagrados, e sua escrita pode ter sido motivadora de risos em seu tempo de produção. A vingança do riso proposta por Bergson não pode ser excluída na leitura de textos em que a ridicularização de estratos sociais elevados e/ou opressores é narrada. Os processos de tradução, canonização e de sacralização pode, em muitos casos, amenizar o caráter do cômico ou até mesmo suprimi-lo em sua interpretação. 
Mary Beard (2014) afirma que aquilo que era capaz de produzir riso na Roma antiga, hoje pode provocar horror. O contexto da piada tem que ser levado em conta. As características subjetivas estão perdidas no tempo. Não conseguiremos compreender o riso na Roma antiga, pois não vivemos na Roma antiga. A historiografia pode colaborar tentando desvendar do que se ria, partindo de uma certeza inalienável: a civilização romana no nascedouro do cristianismo ria, e ria muito.

Podemos encontrar aspectos do risível nos textos do cristianismo a partir da farta utilização de ironias, sarcasmos e sátiras existentes nos mais variados relatos. Bergson aponta que esses elementos têm a função de transpor a realidade e confrontar os limites impostos. O riso irônico é visto como uma característica elevada do cômico, indo do burlesco até o sarcasmo. A recepção, no entanto, durante os anos, tratou de acobertar esses elementos, ou de "traduzi-los" de maneira a não evidenciar o riso provocado. Eles acabam por serem vistos apenas como figuras de linguagem, como recursos literários menores para explicação e/ou compreensão do texto. Sua carga cômica é reduzida ao extremo. Nos textos do cânon bíblico, especificamente no relato de Marcos, as piadas e os chistes foram colocados sob uma aura de seriedade que lhes retira o verniz do riso. $\mathrm{O}$ endemoniado gera mais comoção que riso, a cura do gago mais compaixão que sorriso.

\section{O Evangelho de Marcos entre dois mundos}

No relato marquino, a ironia do riso surge tanto na possiblidade de vingança a que Bergson se refere como na possibilidade de se expandir e/ou romper fronteiras. O endemoniado e sua situação são risíveis, pois aderem a essas duas características.

Na obra Mark as Story, David Rhoads, Joanna Dewey e Donald Michie afirmam que em Marcos se inicia o gênero "evangelho", assim como suas características socioculturais e diversidade de estilos que compõem a narrativa. Para eles, a diversidade de gêneros literários nos relatos constantes no Evangelho de Marcos pode ser sentida pela audiência/leitor no contato com o texto. Marcos tem uma boa estória para contar e, ao mesmo tempo, apesar da construção trágica de seu personagem, correspondendo à expectativa messiânica de seu tempo, não se esquece das ironias e do sarcasmo, e não destitui o cômico da narrativa. Ele tem a leveza e profundidade da ironia que provoca o riso, ao mesmo tempo em que conduz a audiência/leitor a vivenciar o horror da paixão e morte.

Em Mark as story os autores colocam essa característica de Marcos, a da boa estória a ser contada, como sendo a força primordial na construção da 
narrativa. Para ele, a estruturação do herói, o encadeamento dos fatos sem a preocupação cronológica e a falta de conexão entre as cenas justificam o objetivo do redator de contar a estória do Cristo, o Messias, e que todos devem se identificar com ele e o seguir.

A construção da narrativa a partir da oratória tem os elementos que Quintiliano percebeu em suas Instituciones Oratoria : são cenas curtas, que fazem um todo, mas que possuem sentido na sua particularidade. Funcionam quase como esquetes isoladas que compõem um grande drama. A narrativa vai da ironia ao trágico, do humor ao horror. A coerência está na capacidade de nos prendermos à estória pelos mais variados sentimentos. Uma montanha-russa composta de momentos nos quais as ações são, na acepção aristotélica do termo, elevadas e interrompidas por diálogos absurdos com gagos, endemoniados, surdos, coxos etc. $\mathrm{Na}$ forma literária, concordando com Harold Bloom, que o compara à obra de Edgar Alan Poe, mesmo não sendo um grande escritor Marcos tem a capacidade de prender a atenção e produzir a mais ampla variedade de sentimentos. Nesse evangelho, esses conceitos que podem parecer tão díspares encontram-se e produzem sentido, criam condições para que o relato tenha verossimilhança, que se torna infinitamente mais importante que o factível (BLOOM, 2006).

Marcos rompe com um mundo estruturado, rompe os limites dessa imposição e demonstra o quanto é diverso o ambiente em que se passa a estória. O Cristo de Marcos, apesar de, como diz, ser mais fidedigno ao Javé do Antigo Testamento, não pode ser um emissário apenas ao povo de Israel (BLOOM, 2006). O universo se expandiu, e Marcos percebe que isolar a narrativa à realidade de Israel apequena Deus. É necessário expandir-se e usar outras culturas para propagar o Messias e sua boa-nova ao mundo.

Tanto para Bloom como para Rhoads, Dewey e Michie, Marcos, ao inaugurar o gênero evangelho, tem um olhar sobre as tradições culturais que o prendem ao seu passado hebraico, a espera de um Messias que virá e que será trágico, mas que, ao mesmo tempo, convive com um universo que não é mais exclusivo de sua referência cultural.

O ambiente em que o personagem Cristo atua é de absoluta diversidade. O contato com outras culturas não pode mais ser controlado. A multiculturalidade traz consigo outras formas narrativas que, colocadas em comunicação com as já conhecidas, moldam a construção do Evangelho de Marcos.

Essa diversidade de estilos é amplamente empregada para a construção narrativa. No relato de Marcos, no seu ambiente de cultura popular que carnavaliza os estilos, tem espaço o herói trágico, o horror de seu sacrifício e a legio travestida como um bufão endemoniado; tem espaço o sublime na 
cura da mulher que toca a veste de Cristo e o irônico diálogo com a outra mulher, a siro-fenícia; tem espaço longas digressões do Cristo como personagem principal, tal como nos sermões e na voz do público que o anuncia como Rei e, do mesmo modo, salva Barrabás. São contempladas as formas de expressões poéticas elevadas, como prevê a crítica aristotélica, e o monstruoso e abjeto que habitam os cemitérios. Têm espaço o sagrado e o profano, o grotesco e o sublime.

\section{$O$ riso na narrativa do endemoniado geraseno}

A narrativa de exorcismo executado por Jesus e que é constante no Evangelho de Marcos 5.1-20 pode ser resumida da seguinte maneira:

Jesus, ao chegar à terra do gerasenos, é interpelado por um homem que todos diziam estar possuído por demônios. Nada o segurava, nem correntes. Vivia nu e entre as sepulturas de um cemitério. Vagava noite e dia, e às vezes se feria. Ao ver Jesus, o reconheceu e perguntou: "O que você quer comigo?". Cristo ordena que o espírito que o possuía saia dele, mas antes pergunta quem ele é. Ele responde: "Legião, porque somos muitos". Estes pedem para Cristo que não os mande para fora do país. Cristo, vendo ao lado uma manada de porcos, expulsa os demônios do homem e coloca-os nos animais, que se atiraram num precipício em direção ao mar, onde se afogam. O homem recupera o juízo, senta-se ao lado de Cristo e os criadores de porcos correm para avisar a todos o que havia acontecido, e todos pedem que Cristo se retire de suas terras. O que fora endemoniado pede para acompanhar Cristo, mas este nega, pedindo que ele conte a todos o acontecido.

Muitas interpretações foram feitas a partir desse texto, mas poucas se atém ao caractere do risível aí perceptível. Sua construção está repleta de ironias e de vingança, no sentido que Bergson atribui.

Uma característica marcante da presença da ironia no texto é o fato de o demônio possessor reconhecer o Messias antes e, na sequência, apresentar-se como legio, legião. Esse demônio corre e adora o Messias, reconhece-o, pois ambos são estrangeiros. Outra relação que se pode fazer é com o texto de 3.22: "Os escribas que haviam descido de Jerusalém, diziam: Ele está possesso de Belzebu. É o maioral dos demônios que expele os demônios". A ironia que o redator propõe é a do Cristo que é reconhecido como um demônio no capítulo 3 , e que se conecta ao capitulo 5 . Um demônio tem capacidade de reconhecer outro. Considerando-os como seres que habitam fronteiras, os dois se reconhecem mutuamente.

A outra ironia a ser destacada no texto é mais nítida: colocar o dominador romano como uma entidade incorporada em um ser que habita 
um cemitério, a periferia; ridicularizar o poderio romano, marginalizando-o como um ser louco que, desnudo e desprovido de toda a importância de suas vestes, caminha entre túmulos e mortos. Invertem-se os papeis sociais. O centro vira periferia. Outra vez se nota a vingança risível a que Bergson se refere. O poder romano é confrontado na borda da sociedade, naquilo que ela excreta e que marginaliza.

Esse caráter irônico expresso no texto não pode, apesar do diálogo absurdo travado entre os interlocutores, provocar o riso franco partindo das configurações culturais da atualidade. Aquilo que podia ser um escracho com a figura dos romanos é romantizado e retirado de um contexto do risível. Esse mesmo relato, quando proferido em uma roda de conversa, poderia provocar risos imensos com as situações inusitadas apresentadas e com a ridicularização daqueles que detinham o poder e oprimiam.

As evidências da ironia e do sarcasmo continuam: os porcos, após serem “infestados" por demônios, são atirados em um precipício inexistente, que chega a um mar igualmente inexistente. A inexatidão geográfica soa como o brasileiríssimo "mar de minas". Os demônios que pedem para não serem levados para longe dão espaço à última ironia do texto: os porqueiros e a população pedem para que Cristo vá para longe. A narrativa, que tem o demônio implorando para não ser enviado para longe, tem o Cristo sendo expulso para longe. A chave de interpretação dessa narrativa como risível não pode ser desconsiderada.

\section{Considerações finais}

Todos os críticos que se debruçaram sobre a temática do riso (Minois, Berger, Bergson, Sarrazin, Alberti, Bataille, entre outros) são unânimes ao afirmar que, quando se estuda o riso, ele perde a graça. O riso é muito volátil, e necessita-se compreender uma infinidade de questões objetivas e subjetivas que o produzem. $\mathrm{O}$ riso em textos sagrados passa quase que totalmente despercebido. Seguindo a lógica de encadeamento das tensões narrativas, ele pode, em excesso, explodir com o texto. O que sobra são pequenos traços. A trama textual da literatura sagrada e a recepção sacralizada/séria não permitem o riso. Os aspectos culturais, sociais e religiosos devem estar sempre na análise do riso. Uma piada que fora motivo de riso na antiguidade pode, nos dias de hoje, provocar horror e terror, e na sua incompreensão surge a pergunta: riam disso?

Não conseguiremos, dentro da nossa realidade cultural, rir abertamente de textos sagrados, principalmente daqueles que fazem parte do cânon. 
A demonização do riso que Minois adverte ter ocorrido na Idade Média, sobremaneira nos textos bíblicos, colabora para a visão atual que o marginaliza nesses textos e diminui seu caráter jocoso, satírico e irônico, mas em nenhuma hipótese deve impedir sua identificação como componente elevado da literatura bíblico-religiosa.

Contribuiu para essa demonização do riso a visão neoplatônica da religiosidade ocidental. Rir afasta o indivíduo da possibilidade de ascese. $\mathrm{O}$ riso atua como um impeditivo para a superação, prende o espírito à carne. Rir extrapola limites sociais e os questiona. Georges Bataille (2005) abre uma nova perspectiva ao colocar o riso como, rompendo com a razão, um caminho para o transcendente.

Não se pode isolar as pesquisas da realidade que cerca a formação da moldura social e religiosa. No cotidiano as pessoas riem. Riem para mostrar sua superioridade; riem ao se automatizar ou ao se animalizar; riem dos outros e de si mesmas. Riem do absurdo de suas existências. Riem ao entrarem atrasadas em um teatro e perceber que todos já estão rindo. Rir provoca risos.

\section{Referências bibliográficas}

ALBERTI, Verena. O riso e o risivel na história do pensamento. Rio de Janeiro: Zahar; Editora da Fundação Getulio Vargas, 1999.

ARISTÓTELES. Poética. Coleção “Os pensadores”. São Paulo: Nova Cultural, 1999.

BAKHTIN, Mikhail. A cultura popular na idade média e no renascimento: o contexto de François Rabelais. São Paulo: Hucitec; Editora da UnB, 1987.

BAKHTIN, Mikhail. Estética da criação verbal. São Paulo: Martins Fontes, 2006.

BATAILLE, Georges. Lo limite de lo útil. Buenos Aires: Editorial Losada, 2005.

BHABHA, Homi. O local da Cultura. Belo Horizonte: Editora da UFMG, 1998.

BEARD, Mary. Laughter in ancient Rome. Los Angeles: University of California Press, 2014.

BERGSON, Henri. O riso: ensaios sobre a significações do cômico. Rio de Janeiro: Zahar, 1980 .

BETZ, Hans Dieter. The Greek Magical Papyri in translation - including Demotic spells. Chicago: The University of Chicago Press, 1986.

BLOOM, Harold. Abaixo as verdades sagradas. Trad. Alípio Correa de Franca Neto e Heitor Ferreira da Costa. São Paulo: Companhia de Bolso, 2012.

BLOOM, Harold. Onde encontrar a sabedoria. Trad. José Roberto O’Shea. Rio de Janeiro: Objetiva, 2009.

BLOOM, Harold. Jesus e Javé: os nomes divinos. Trad. José Roberto O’Shea. Rio de Janeiro: Objetiva, 2006.

DARWIN, Charles. The expression of the emotions in man and animals. London: John Murray, 1872. 
LOTMANN, Yuri. La semiosfera I. Semiótica de la cultura y del texto. Valencia: Fronesis, 1986.

MINOIS, Georges. História do riso e do escárnio. São Paulo: Editora da Unesp, 2003.

MACEDO, José Rivair. Riso ritual, cultos pagãos e moral cristã na Idade Média. Boletim CPA, Campinas, n. 4, p. 87-111, 1997.

NOGUEIRA, Paulo A. S. (Org.). Linguagens da religião: desafios, métodos e conceitos centrais. São Paulo: Paulinas, 2012.

QUINTILIANO, M. Fabio. Instituciones Oratoria. Trad. Ignacio Rodriguez y Pedro Sandier. Madrid: Imprensa de Perlado Páez y Compañia, 1916.

RHOADS, David; DEWEY, Joanna: MICHIE, Donald. Mark as story: introduction to the narrative of a gospel. Minneapolis: Fortress Press, 2012.

SALIBA, Elias Tomé. História cultural do humor: balanço provisório e perspectivas de pesquisas. Revista História da USP, São Paulo, n. 176, p. 1-39, 2017.

SKINNER, Quentin. Hobbes e a teoria clássica do riso. Trad. Alessandro Zir. São Leopoldo: Editora da Unisinos, 2002.

Submetido em: 27-2-2020

Aceito em: 5-5-2020 